\title{
AS TECNOLOGIAS DIGITAIS DA INFORMAÇÃO E COMUNICAÇÃO NA FORMAÇÃO DO PROFESSOR DE MATEMÁTICA EM CURSOS A DISTÂNCIA
}

\author{
Elivelton Henrique Gonçalves ${ }^{1}$ \\ Fabiana Fiorezi de Marco ${ }^{2}$
}

\begin{abstract}
Resumo - A Educação a Distância é uma modalidade de educação que gradativamente está se destacando no cenário atual brasileiro, uma vez que impulsionada pelo desenvolvimento das novas tecnologias, propicia ao aluno realizar seus estudos em seu próprio tempo, adaptandose a diferentes realidades. Este artigo tem como objetivo contribuir e fomentar com a discussão sobre a importância da formação inicial dos professores para uso das Tecnologias Digitais da Informação e Comunicação no âmbito da Educação a Distância. Trata-se de uma pesquisa bibliográfica, com abordagem qualitativa, cujos indícios apontam para a necessidade de não apenas oferecer formação por intermédio dos meios tecnológicos digitais, mas, também, proporcionar formação acerca do uso de tais tecnologias, de modo a permitir uma possível utilização daquelas, pelos futuros professores de Matemática, em sua prática docente.
\end{abstract}

Palavras-chave: Educação a Distância; Tecnologias Digitais da Informação e Comunicação; Formação de professores de Matemática.

\section{DIGITAL TECHNOLOGIES OF INFORMATION AND COMMUNICATION IN MATHEMATICS TEACHER DEVELOPMENT IN DISTANCE LEARNING COURSES}

Abstract - Distance Learning is an educational modality that is gradually being highlighted in the current Brazilian educational scenario, since impulsed by the development of new technologies, it allows students to study in their own time, adapting to different realities. This article aimed to contribute with the discussion about the importance of the initial development of teachers for the use of Digital Technologies of Information and Communication in the scope of Distance Learning. It is a bibliographical research with a qualitative approach, whose indications point to the need no only to offer formation through digital technological means, but also to provide formation about the use of such technologies, in order to allow a possible use of them by future Mathematics teachers in their teaching practice.

Keywords: Distance Learning; Digital Technologies of Information and Communication; Mathematics teacher development.

\section{INTRODUÇÃO}

As modernas tecnologias digitais estão cada vez mais presentes na sociedade atual e chegam às escolas por meio de sua utilização pelos alunos, levando um novo desafio aos professores: “como incorporá-las em sua prática pedagógica de forma significativa e não

1Mestrando em Educação pelo Programa de Pós-Graduação em Educação da Universidade Federal de Uberlândia (UFU). Graduado em Matemática pela Faculdade Patos de Minas (FPM). eliveltonhg@hotmail.com 2Doutora em Educação pela Universidade Estadual de Campinas (UNICAMP). Professora do Programa de PósGraduação em Educação da Universidade Federal de Uberlândia (UFU). fabiana.marco@ufu.br 
apenas como uma ferramenta para motivar a sua aula ou transmitir conteúdos?” (CANTINI et al., 2006, p.877). Entendemos ser preciso que as Tecnologias Digitais da Informação e Comunicação (TDIC) sejam utilizadas de modo dinâmico, criativo, inovador, onde a sala de aula possa se tornar um ambiente interativo na construção da aprendizagem.

Nesta perspectiva, surge a necessidade dos professores de Matemática e também das demais áreas, estarem preparados para lidarem com esse cenário tecnológico que não é mais tão novo. É importante que na formação inicial ${ }^{3}$ (e/ou continuada) os professores de Matemática vivenciem, explorem, interajam com as novas tecnologias, para que tenham a possibilidade de desenvolver habilidades para seu uso e se sintam seguros de incorporá-las à sua futura prática docente (MARTINI; BUENO, 2014).

Os avanços das TDIC influenciaram também, o desenvolvimento da educação superior à distância no Brasil. Diante disso, afirmam Zabel e Almeida (2015), houve, nos últimos anos, uma expansão na oferta de cursos de formação inicial de professores a distância no país. Assim, por meio da Educação a Distância (EaD) associada às novas tecnologias, “[...] tendo encontrado maior força a partir do uso da internet como forma de comunicação nos cursos, [...] tornou possível a realização de diversos cursos de formação [...]” (ZABEL; ALMEIDA, 2015, p.47) para professores.

Este artigo tem como objetivo contribuir e fomentar com a discussão sobre a importância da formação inicial dos professores para uso das TDIC no âmbito da EaD. Tratase de uma pesquisa bibliográfica, com abordagem qualitativa. Ressaltamos que, neste estudo, adotaremos o termo Tecnologia Digital da Informação e Comunicação (TDIC), ao que a bibliografia chama de Tecnologia da Informação e Comunicação (TIC), posto que ao rigor da sigla, TDIC, englobam as tecnologias digitais (AFONSO, 2002). Todavia, manteremos as siglas TIC e NTIC (Novas Tecnologias de Informação e Comunicação) nas citações diretas e indiretas.

\section{A EDUCAÇÃO A DISTÂNCIA}

A Educação a Distância (EaD) é uma modalidade de Educação na qual professores e alunos estão separados fisicamente no espaço e/ou tempo, é realizada atualmente, predominantemente por meio do uso das TIC e pode ter, ou não, momentos presenciais

3 Quando utilizamos a expressão formação inicial, não estamos desconsiderando que, ao ingressar em um curso de licenciatura, o futuro professor tenha consigo crenças, ideias, imagens sobre o que é ensinar, aprender e ser um bom professor, resultante dos anos de escolarização (das memórias e experiências quando aluno e/ou professor) (MARCELO, 1998). 
(MORAN, 2002). A EaD surgiu oficialmente no Brasil em 1996 (ALVES, 2011), cujas bases legais para essa modalidade de Educação foram estabelecidas pelo artigo 80 da Lei de Diretrizes e Bases da Educação Nacional n 9.394, de 20 de dezembro de 1996 (BRASIL, 1996), sendo regulamentada pelo Decreto $n^{\circ} 5.622$ de 20 de dezembro de 2005 (BRASIL, 2005).

O Decreto $n^{\circ} 5.622$ de 20 de dezembro de 2005, conceitua a EaD como:

Art. $1^{\circ}$ Para os fins deste Decreto, caracteriza-se a educação a distância como modalidade educacional na qual a mediação didático-pedagógica nos processos de ensino e aprendizagem ocorre com a utilização de meios e tecnologias de informação e comunicação, com estudantes e professores desenvolvendo atividades educativas em lugares ou tempos diversos (BRASIL, 2005).

Com a expansão da Internet, permitiu-se uma nova configuração à $\mathrm{EaD}$, que antes realizava-se por correspondência, transmissão de aula via satélite e materiais didáticos impressos, fitas de áudio, dentre outras (VIOL; MISKULIN, 2012). Com os avanços tecnológicos, principalmente das Tecnologias Digitais, a EaD, atualmente, possibilita a interação entre tutores, professores, alunos, a realização de atividades e acesso a conteúdos diversos disponibilizados no Ambiente Virtual de Aprendizagem (AVA), plataformas computacionais desenvolvidas para os cursos a distância (ALMEIDA; BORBA, 2015) e, também, pelas diversas possibilidades e informações que podem ser acessadas pela Internet.

Assim, neste trabalho, quando nos referimos a EaD, estaremos nos reportando a essa modalidade que se realiza via internet, por meio dos Ambientes Virtuais de Aprendizagem, viabilizada, principalmente, devido aos avanços da tecnologia, em especial, as tecnologias digitais (ALMEIDA; BORBA, 2015), a qual Borba, Malheiros e Zulatto (2007) denominam de EaD online.

Almeida e Borba (2015) afirmam que o avanço na EaD no Brasil, se realizou em grande parte com a criação da Universidade Aberta do Brasil (UAB). A UAB é um sistema integrado por universidades públicas brasileiras que oferece cursos de nível superior, por meio da Educação a Distância. A UAB foi criada pelo Decreto 5.800, de 08 de junho de 2006, para “o desenvolvimento da modalidade de educação a distância, com a finalidade de expandir e interiorizar a oferta de cursos e programas de educação superior no País” (BRASIL, 2006). A prioridade do Sistema UAB, ainda de acordo com Brasil (2006), é a formação inicial ou continuada de professores da educação básica, seguidos dos dirigentes, gestores e trabalhadores em educação básica dos estados, municípios e do Distrito Federal. 
A EaD vem se tornando uma grande aliada no processo de formação, tanto inicial como continuada, de professores. Zabel e Almeida (2015) apresentam dois principais fatores para tal cenário: a possibilidade de oferecer formação a professores distantes geograficamente dos centros universitários com custos reduzidos; e, a oportunidade de professores, com elevada carga horária de trabalho, adequarem seus horários para a realização de um curso de formação de qualidade por intermédio dos cursos ofertados pela UAB.

Deste modo, a EaD pode permitir o acesso a educação de nível superior público, colaborar para que a formação aconteça às pessoas sem a necessidade do deslocamento de sua região (ALVES, 2011). E isso é permitido, em grande parte, pelas TDIC que proporcionam novas possibilidades para o ensino e aprendizagem a distância, uma vez que a utilização destas tecnologias pode facilitar o diálogo, propiciar maior interatividade, facilitar o acesso às informações em função de novos recursos tecnológicos surgirem, frequentemente ou outros serem aprimorados (VIEIRA, 2011).

\section{A FORMAÇÃO DE PROFESSORES DE MATEMÁTICA E ÀS TECNOLOGIAS DIGITAIS DA INFORMAÇÃO E COMUNICAÇÃO}

As Diretrizes Curriculares Nacionais (DCN) para a formação inicial em nível superior (cursos de licenciatura, cursos de formação pedagógica para graduados e cursos de segunda licenciatura) e para a formação continuada (BRASIL, 2002, 2015), destacam a necessidade dos cursos de formação proporcionar aos futuros professores condições nas quais possam aprender a utilizar as tecnologias de informação e comunicação, “cujo domínio é importante para a docência e para as demais dimensões da vida moderna” (BRASIL, 2002, p.45).

Quando as DCN (BRASIL, 2015) tratam da formação dos profissionais do magistério para Educação Básica, é mencionado que a formação deve conduzir o egresso ao "uso competente das Tecnologias de Informação e Comunicação (TIC) na perspectiva de aprimoramento da prática pedagógica e da ampliação da formação cultural dos/das professores/as e estudantes” (BRASIL, 2015, p.6). Ao tratar do egresso dos cursos de formação inicial em nível superior, espera-se que os licenciandos estejam aptos a "relacionar a linguagem dos meios de comunicação à educação, nos processos didático-pedagógicos, demonstrando domínio de adequadas tecnologias de informação e comunicação para o desenvolvimento da aprendizagem” (BRASIL, 2015, p.8). Fica evidenciada, a necessidade dos cursos de formação inicial criar um "projeto formativo assegurando aos estudantes o 
domínio dos conteúdos específicos da área de atuação, fundamentos e metodologias, bem como das tecnologias” (BRASIL, 2015, p.10).

Dessa forma, é importante que os cursos de graduação em Licenciatura (de Matemática, no nosso caso) promovam formação para a utilização das tecnologias digitais, estabelecendo vínculos entre a teoria e a prática (MARTINI; BUENO, 2014). Marco (2009) nos aponta a necessidade de propiciar aos futuros professores de Matemática situações de formação para o uso das novas tecnologias, nas quais sejam desafiados e possam desempenhar um papel ativo, de modo a despertarem o seu senso crítico diante da utilização de tais tecnologias. Haja vista que os futuros professores de Matemática "constroem seu conhecimento sobre o ensino da Matemática através de suas experiências com o ensino” (D’AMBRÓSIO, 1993, p.39), por meio de suas experiências, vivências, reflexões teóricas e práticas no seu processo formativo (MARCO, 2009).

Portanto, é importante que seja assegurada na formação inicial de professores de Matemática a possibilidade, dos futuros professores, conhecer, desenvolver, implementar, acompanhar e avaliar estratégias didático-pedagógicas que oportunizam a aquisição de habilidades para a utilização das novas tecnologias digitais no ambiente escolar e à apropriação dessas dentro de suas práticas (CUNHA, 2015).

Marco (2009) ainda destaca que é necessário que os cursos de formação de professores de Matemática, não propiciem somente o domínio de técnicas ou somente conhecimentos teóricos das mais diversas tecnologias, bem como, suas potencialidades no ensino da Matemática. Há a necessidade também, continua a autora, que os cursos ofereçam ao futuro professor momentos de vivência, exploração, reflexão teórico-metodológica acerca dessas tecnologias, para que assim possam conhecer sua contribuição "para a e na sala de aula” (MARCO, 2009, p.20, grifos da autora) e, tenham a possibilidade de, posteriormente, produzir suas próprias atividades, apropriando e aliando as novas tecnologias digitais ao ensino de Matemática.

Contudo, a utilização das novas tecnologias nos cursos de licenciatura, afirma Ramos, Barroqueiro e Amaral (2011), ainda se mostram incipientes. As novas tecnologias, dependendo do seu uso, podem ser empregadas de diversas maneiras e como elemento de mudança das práticas educativas em diferentes contextos do ensino. Entretanto, nas escolas é comum encontramos “docentes desplugados, ensinando a alunos que surfam na Internet” (CHASSOT, 2003, p.90, grifos do autor). Assim, na formação dos professores que trabalham e/ou trabalharão com a geração que nasce e vive mergulhada no mundo das novas tecnologias, 
torna-se necessário que os recursos das TIC sejam abordados em sua formação inicial, como também, na formação continuada (RAMOS; BARROQUEIRO; AMARAL, 2011).

As tecnologias, afirma Moran (2004), estão colocadas nas escolas e nas universidades, contudo, na maioria das vezes, é “o professor falando e o aluno ouvindo, com um verniz de modernidade” (MORAN, 2004, p.2); o uso (quando há) das tecnologias se resume muitas vezes em ilustrar os conteúdos transmitidos pelo professor e não para a criação de novos caminhos e oportunidades para o ensino e aprendizado. Desse modo, acreditamos que quando os professores, em seu processo formativo, experienciam e estão envolvidos com o uso das TDIC, conduzindo-os a aquisição de habilidades e reflexão teórica-prática, têm-se maiores possibilidades que sua utilização, na futura prática desses profissionais, aconteça de maneira inovadora e criativa.

\section{A FORMAÇÃO DO PROFESSOR DE MATEMÁTICA NA EDUCAÇÃO A DISTÂNCIA}

A formação inicial (ou continuada) de professores na EaD, ocorre principalmente via AVA. Esses ambientes virtuais, segundo Viol e Miskulin (2013), têm-se apresentado como locais favoráveis à composição de ambientes formativos, que podem propiciar e potencializar aspectos referentes à formação de professores.

Zabel e Almeida (2015) destacam que a utilização de tecnologias na EaD nos cursos de Matemática ocorre em duas frentes: (i) estão presentes no AVA, com destaque aos fóruns de discussão e chats, ou seja, como forma de interação entre professor, tutor e aluno e, (ii) relacionados com a utilização de vídeoaulas e softwares matemáticos como material de apoio ao conteúdo disponibilizados no AVA. É possível, afirma Vieira (2011), que esses futuros professores levem consigo essa experiência, esse contato, com a comunicação online e o material disponibilizado no ambiente virtual para sua prática profissional, utilizando as TIC com criatividade e desenvolvendo ações educativas inovadoras.

Contudo, como já citamos anteriormente, acreditamos que quando os professores têm situações de vivência, exploração e reflexão sobre a utilização das TDIC em seu processo de formação, têm-se maiores possibilidades de proporcionarem, aos seus futuros alunos, uma aprendizagem mais significativa por meio do uso das TDIC. Pretto (2001, p.49 apud VIOL; MISKULIN, 2012, p.05) nos alerta que 
[...] não podemos correr o risco de desenvolver mecanismos para alfabetizar mecanicamente a população para o uso dessas tecnologias e, com isso, estarmos formando, num futuro bem próximo, um novo contingente de analfabetos, agora os analfabetos funcionais digitais, aqueles que serão meros operadores das máquinas, que aprendem a usar as tecnologias como simples instrumentos mas que, no fundo, vão estar permanentemente na parte de baixo dessa pirâmide social que continua com a mesma formatação, dando muito a poucos e quase nada a quase todos. Penso que os programas de EaD são fundamentais como possibilidade de estabelecimento de uma grande rede, que articule o sistema público de ensino e as universidades públicas, em especial as faculdades que formam professores.

Paulin e Miskulin (2015) alegam ser importante que o processo de formação inicial de professores de Matemática a distância, propicie aos licenciandos a possibilidade de terem contato e construírem uma identidade no ciberespaço. Desse modo, os licenciandos poderão ter a possibilidade de refletirem sobre as potencialidades e interagirem com as TDIC, oportunizando-os por meio da vivência e exploração de tais tecnologias, a possibilidade de desenvolver ou aprimorar habilidades que os permitirão utilizá-las na sua futura prática docente, no processo de ensino e aprendizagem da Matemática. Assim, o que se busca é a formação que promova a integração das tecnologias digitais nas ações de ensino dos futuros professores (CABANHA; SCHERER, 2014).

As TDIC pressupõem

[...] novas formas de gerar e dominar o conhecimento. O desenvolvimento tecnológico proporciona uma nova dimensão ao processo educacional, a qual transcende os paradigmas ultrapassados do ensino tradicional, pontuado pela instrução programada, transmissão de informações e "treinamento" do pensamento mecânico. Com o avanço da ciência e da tecnologia, [...] entendemos que a Educação precisa ser redimensionada. Essa nova dimensão necessita priorizar um novo conhecimento, que considera o desenvolvimento do pensamento criativo como aspecto fundamental da cognição humana (MISKULIN; VIOL, 2014, p.1313).

Nessa perspectiva, há a necessidade de que os professores estejam abertos à novos modos de organizar e de administrar as aulas, com inovação e criatividade, adotando uma nova postura frente os recursos disponíveis, "novas maneiras de gerar e dominar o conhecimento, novas formas de produção e apropriação do conhecimento na prática docente, isto se não quiserem ficar estagnados em métodos de ensino e teorias de trabalhos obsoletos” (MISKULIN; VIOL, 2014, p. 1313).

Marco (2009) nos afirma que a sociedade vem gradativamente exigindo um ensino de Matemática, no qual as novas gerações sejam preparadas para lidarem com os ambientes computacionais, com a realidade virtual, com o computador; "que forme indivíduos que 
pensem de forma flexível, crítica, eficaz e criativa” (MARCO, 2009, p.17). Contudo, a autora nos adverte que o ensino da Matemática atualmente, continua centrado na memorização de fórmulas, no conteúdo, no formalismo lógico, assim como foi no século passado. A Matemática ainda continua sendo temida por muitos alunos e está entre as disciplinas que apresentam os maiores índices de reprovação, deste modo, há a necessidade de alternativas que contribuam para alterar esse cenário (MARTINI; BUENO, 2014).

As TDIC, por sua vez, podem contribuir com a criação de ambientes mais interativos, dinâmicos, oferecendo ferramentas de suporte ao processo de ensino e aprendizagem, contribuindo com a construção do conhecimento matemático. Contudo, o uso das TDIC não resolverão todos os problemas com o ensino e aprendizagem da Matemática, delineados acima (MARTINI; BUENO, 2014). Porém, as experiências com a vivência e exploração, os questionamentos e reflexões, acerca da utilização das TDIC pelos professores no seu processo formativo, podem influenciar de modo significativo à maneira como se apropriam das TDIC em sua prática docente; caminhando, dessa forma, "para um processo de mudança no fazer e no pensar relacionado ao processo de ensino e aprendizagem da Matemática que privilegie o uso das TIC”, criando situações interativas, colaborativas e investigativas baseadas nas TDIC (MISKULIN; VIOL, 2014, p.1326).

Paulin e Miskulin (2015, p.1109) destacam um desafio que está presente no campo da formação de professores: a promoção e criação de contextos de ensino e aprendizagem e investigação em que "os futuros-professores e/ou os professores em Formação Continuada sejam levados a transformarem o grande número de informações disponíveis em conhecimento crítico que poderá conduzir à uma possível (res)significação da prática docente em sala de aula.” Pois, vivemos, atualmente, em uma sociedade na qual gradualmente os mais avançados equipamentos tecnológicos vão intensificando sua presença na vida das pessoas; e nas escolas não é diferente,

As novas tecnologias vão, aos poucos, incorporando-se ao dia-a-dia da sala de aula e por isso devem ser tratadas, testadas e estudadas nos cursos de Licenciatura em Matemática. Tal prática faz com que professores e alunos se sintam preparados e motivados para o seu uso, o que permitirá, aos futuros licenciados, uma melhor preparação para suas atividades [...] (CLÁUDIO; CUNHA, 2001, p.169-170).

Miskulin e Viol (2014) salientam que a participação de professores e futuros professores em situações de formação que privilegiam experiências e vivências educativas, permeadas pelas novas tecnologias digitais, permite que, gradativamente, se apropriem das 
TDIC em sua prática de sala de aula. Entretanto, trata-se de uma apropriação das TDIC de maneira crítica e reflexiva, que conduz a novas formas de exploração e construção do saber matemático em sala de aula.

\section{CONSIDERAÇÕES FINAIS}

Acreditamos que na formação inicial (e/ou continuada) dos professores de Matemática, seja de grande importância a criação de um diálogo, uma conexão entre os conhecimentos matemáticos e as novas tecnologias, aliando os recursos tecnológicos às experiência e conteúdos no ambiente escolar.

Entendemos, ainda, que há a necessidade de não apenas oferecer formação, via EaD, aos futuros professores através de meios tecnológicos. Todavia, é preciso também que se proporcione a eles formação acerca da utilização de tais tecnologias, de modo a auxiliá-los à inserção daquelas em sua futura prática docente de maneira criativa e inovadora. As TDIC podem enriquecer o espaço escolar, porém “sozinhas elas são apenas ferramentas, mas se bem utilizadas, elas podem colaborar para que haja de fato uma mudança radical no processo ensino-aprendizagem” (VIEIRA, 2011, p.67). Assim, a formação para o uso das TDIC tornase imprescindível.

Nesse sentido, nosso intuito nesse texto foi contribuir e fomentar com a discussão sobre a importância da formação inicial dos professores para uso das TDIC no âmbito da $\mathrm{EaD}$, no qual a formação acontece, prioritariamente, por meios tecnológicos. Além de suscitar a necessidade de despertar nos licenciandos a curiosidade, a pesquisa, o incentivo ao novo, a prática de ideias inovadoras, a postura criativa e uma relação possível entre os conhecimentos matemáticos e às TDIC.

\section{REFERÊNCIAS}

AFONSO, Carlos A. Internet no Brasil: alguns dos desafios a enfrentar. Informática Pública, Belo Horizonte, v. 04, n. 02, p. 169-184, 2002.

ALMEIDA, Helber Rangel Formiga Leite de; BORBA, Marcelo de Carvalho (Orgs.). Elicm@t. As Licenciaturas em Matemática da Universidade Aberta do Brasil (UAB): uma visão a partir da utilização das Tecnologias Digitais. São Paulo: Editora Livraria de Física, 2015. p. 13-28. 
ALVES, Lucineia. Educação a distância: conceitos e história no Brasil e no mundo. Revista Brasileira de Aprendizagem Aberta e a Distância, São Paulo, v. 10, p. 83-92, 2011.

BORBA, Marcelo de Carvalho; MALHEIROS, Ana Paula dos Santos; ZULATTO, Rúbia Barcelos Amaral. Educação a distância online. Belo Horizonte: Autêntica, 2007.

BRASIL. Decreto 5.622, de 19 de dezembro de 2005. Regulamenta o artigo 80 da Lei n9.394, de 20 de dezembro de 1996, que estabelece as diretrizes e bases da educação nacional. Brasília, DF, 2005.

Decreto 5.800, de 08 de junho de 2006. Dispõe sobre o Sistema Universidade Aberta do Brasil - UAB. Brasília, DF, 2006.

Lei $n^{\circ}$ 9.394, de 20 de janeiro de 1996. Diretrizes e Bases da Educação Nacional. Brasília, DF, 1996. Educação de Jovens e Adultos; Disposições Gerais.

Conselho Nacional de Educação. Parecer CNE/CP 009/2001. Diretrizes Curriculares Nacionais para a Formação de Professores da Educação Básica, em nível superior, curso de licenciatura, de graduação plena. Brasília, DF, 2002.

Conselho Nacional de Educação. Resolução $n^{0}$ 2, de $1^{0}$ de julho de 2015. As Diretrizes Curriculares Nacionais para a formação inicial em nível superior (cursos de licenciatura, cursos de formação pedagógica para graduados e cursos de segunda licenciatura) e para a formação continuada. Brasília, DF, 2015.

CABANHA, Daiane dos Santos Corrêa; SCHERER, Suely. Licenciatura em Matemática na modalidade EaD: um estudo sobre o uso de softwares no Estágio Supervisionado. Revista Brasileira de Aprendizagem Aberta e A Distância, São Paulo, v. 13, p.247-257, 2014.

CANTINI, Marcos Cesar et al. O desafio do professor frente as novas tecnologias. In: CONGRESSO NACIONAL DE EDUCAÇÃO, 6., 2006, Curitiba. Anais... Curitiba: PUC/PR, 2006. p. 875 - 883.

CHASSOT, Attico. Alfabetização científica: uma possibilidade para a inclusão social. Revista Brasileira de Educação, [s.l.], n. 22, p.89-100, abr. 2003.

CLÁUDIO, Dalcídio Moraes; CUNHA, Márcia Loureiro. As novas tecnologias na formação de professores de matemática. In: CURY, Helena Noronha (Org.). Formação de professores de matemática: uma visão multifacetada. Porto Alegre: EDIPUCRS, 2001.p. 167-188.

CUNHA, Maria Francisca da. O papel da tecnologia nos cursos de formação inicial de professores de matemática nas licenciaturas da UNESP. In: ENCONTRO BRASILEIRO DE ESTUDANTES DE PÓS-GRADUAÇÃO EM EDUCAÇÃO MATEMÁTICA, 19., 2015, Curitiba. Anais... Curitiba: UFPR, 2015. p. 1-12.

D’AMBRÓSIO, Beatriz Silva. Formação de professores de matemática para o século XXI: o grande desafio. Pro-posições, Campinas, v. 4, n. 1, p. 35-41, mar.1993.

MARCELO, Carlos. Pesquisa sobre a formação de professores: o conhecimento sobre aprender a ensinar. Revista Brasileira de Educação, n. 9, p. 51-75, set./dez. 1998. 
MARCO, Fabiana Fiorezi de. Atividades computacionais de ensino na formação inicial do professor de Matemática. 2009. 211 f. Tese (Doutorado) - Curso de Doutorado em Educação, Universidade Estadual de Campinas, Campinas, 2009.

MARTINI, Carma Maria; BUENO, José Lucas Pedreira. O desafio das tecnologias de informação e comunicação na formação inicial dos professores de matemática. Educação Matemática Pesquisa, São Paulo, v.16, n.2, p. 385-406, 2014.

MISKULIN, Rosana Giaretta Sguerra; VIOL, Juliana França. As práticas do professor que ensina matemática e suas inter-relações com as tecnologias digitais. Revista Ecurriculum, São Paulo, v. 12, n. 2, p.1311-1330, 2014.

MORAN, José Manuel. O que é Educação a Distância. 2002. Universidade de São Paulo. Disponível em: <http://www2.eca.usp.br/moran/wp-content/uploads/2013/12/dist.pdf>. Acesso em: 17 jun. 2016.

MORAN, José Manuel. Os novos espaços de atuação do professor com as tecnologias. Revista Diálogo Educacional, Curitiba, v. 4, n. 12, p.13-21, 2004.

PAULIN, Juliana França Viol; MISKULIN, Rosana Giaretta Sguerra. Educação a Distância Online e Formação de Professores: práticas de pesquisas em Educação Matemática no estado de São Paulo. Bolema: Boletim de Educação Matemática, Rio Claro, v. 29, n. 53, p.10841114, dez. 2015.

RAMOS, Ivo de Jesus; BARROQUEIRO, Carlos Henrique; AMARAL, Luiz Henrique. As Tecnologias da Informação e Comunicação (TIC) e os institutos e centros federais no cenário de formação de professores de Ciência e Matemática. In: CURI, Edda; AMARAL, Luiz Henrique (Org.). Formação de professores em Ciências e Matemática. São Paulo: Terracota Editora, 2011. p. 59-68.

VIEIRA, Rosangela Souza. O Papel das tecnologias da informação e comunicação na educação a distância: um estudo sobre a percepção do professor/tutor. Revista Brasileira de Aprendizagem Aberta e a Distância, São Paulo, v. 10, p. 65-70, 2011.

VIOL, Juliana França; MISKULIN, Rosana Giaretta Sguerra. Pesquisa em Educação Matemática: um olhar para a Formação de Professores a distância. In: CONGRESSO INTERNACIONAL DE ENSINO DA MATEMÁTICA, 6., 2013, Canoas. Anais... Canoas: ULBRA, 2013. p. 01 - 11.

VIOL, Juliana França; MISKULIN, Rosana Giaretta Sguerra. Potencialidades didáticopedagógicas da Educação a Distância para a formação de professores que ensinam Matemática. In: ENCONTRO NACIONAL DE DIDÁTICA E PRÁTICAS DE ENSINO, 16., 2012, Campinas. Anais..., 2012. p. 01 - 12.

ZABEL, Marília; ALMEIDA, Helber Rangel Formiga Leite de. Um retrato da formação online do professor de Matemática. In: BORBA, Marcelo de Carvalho; ALMEIDA, Helber Rangel Formiga Leite de (Orgs.). As Licenciaturas em Matemática da Universidade Aberta do Brasil (UAB): uma visão a partir da utilização das Tecnologias Digitais. São Paulo: Editora Livraria de Física, 2015. p. 29-47. 